\title{
A ARTE COMO EXPRESSÃO DA VIDA COMO VONTADE DE PODER EM FRIEDRICH NIETZSCHE
}

\author{
Ricardo Evangelista Brandão ${ }^{1}$ \\ Instituto Federal de Pernambuco (IFPE) \\ (iD) https://orcid.org/0000-0003-2217-4661 \\ E-mail: ricardobrand75@gmail.com
}

\begin{abstract}
RESUMO:
O presente artigo pretende investigar a arte como um emblemático exemplo da vida como vontade de poder, segundo a perspectiva de Friedrich Nietzsche. Segundo Nietzsche a vida é um constante criar e recriar sem uma teleologia prédefinida. É justamente por este aspecto que a arte expressa de forma mais transparente o que a vida é, pois, a arte é justamente o processo de criação e recriação sem uma finalidade para além da própria criação. A arte na perspectiva do artista está sempre inconclusa e por isso ele não cessa de criar, é como se o artista de alguma maneira captasse o que a vida é, e revelasse isso em sua arte e no processo de criação. A arte além de ser como tudo o mais, movida pela vontade de poder, na medida em que ela mesma é uma pulsão pelo constante criar, revela de forma muito peculiar o pathos que é a vida como vontade de poder que sempre supera a si mesma. Portanto, o verdadeiro artista ao perceber contra a corrente do mundo a forma como conteúdo e o conteúdo como forma, percebe o mundo invertido, e essa inversão no olhar o possibilita brincar com a vida, criando e transformando o atual em novo. Além disso, na medida em que os valores contrapostos pelo artista são uma mentira necessária para suportar a existência, em sua inversão da realidade encontra a verdadeira realidade em suas inúmeras realidades criadas. Os valores criticados exemplificados pela ação do artista é a concepção de verdade inaugurada pelo Socratismo e Platonismo, que de certa forma é fundamentada em uma espécie de divinização da racionalidade em detrimento do pathos. Nosso filósofo em explícita inversão do Platonismo afirma que a verdade racional-conceitual-metafísica tem menos valor que a irracionalidade do pathos artístico.
\end{abstract}

PALAVRAS-CHAVE: Friedrich Nietzsche; Arte; Vontade de Poder.

\section{ART AS EXPRESSION OF LIFE AS THE WILL OF POWER IN FRIEDRICH NIETZSCHE}

\begin{abstract}
:
This article seeks to investigate art as an emblematic example of life as will to power, from the perspective of Friedrich Nietzsche. According to Nietzsche life is a constant creating and recreating without a pre-defined teleology. It is precisely this aspect that art expresses a more transparent way what life is therefore art is precisely the process of creation and recreation without a purpose beyond creation itself. The art from the perspective of the artist is always unfinished and so he continues to create, is as if the artist somehow would capture what life is, and reveal it in their art and in the creative process. The art besides being like everything else, moved by the will to power, to the extent that she herself is a constant drive by creating, reveals a very peculiar way the pathos that is life as will to power that always surpasses herself . Therefore, to realize the true artist against the current world how content and content as form, realizes the inverted world, and in this reversal look allows play with life, creating and transforming the current New. Furthermore, to the extent that the figures are contrasted by a necessary one photographer to support the existence, for the inversion of true reality is a reality in its many situations created. Criticized the values exemplified by the action of the artist's conception of truth inaugurated by Socratic and Platonism, which in a way is based on a kind of deification of the rational concept. Our Philosopher explicit reversal of Platonism asserts that the truth-conceptual-rational metaphysics has less value than the irrationality of artistic pathos.
\end{abstract}

KEYWORDS: Friedrich Nietzsche; Art; Will to Power.

1 Doutor em Filosofia pela Universidade Federal de Pernambuco (UFPE), Recife - PE, Brasil. Professor de Filosofia do Instituto Federal de Pernambuco (IFPE), Caruaru - PE, Brasil.

BRANDÃO, Ricardo Evangelista. A arte como expressão da vida como vontade de poder em Friedrich Nietzsche. Griot : Revista de Filosofia, Amargosa - BA, v.20, n.2, p.190-201, junho, 2020. 


\section{A vontade de poder em Nietzsche}

Embora nossa meta principal no presente texto seja dissertar acerca da vontade de poder como arte, faz-se necessário explicitar qual a compreensão nietzschiana com os termos vontade e poder, visto que seu entendimento é completamente distinto do entendimento da tradição filosófica sobre eles.

Antes de Nietzsche retrabalhar o conceito, já existia uma tradição bem consolidada a respeito, tradição esta que foi modificando a ideia de vontade no transcorrer da história até chegar à original abordagem do pensador investigado. Começando pela abordagem de Sócrates, que em certo sentido marca o momento em que a filosofia despertou para se debruçar sobre as questões mais relacionadas com o homem, a ideia de vontade parece não fazer muito sentido, todavia, essa falta de sentido, ou melhor, essa específica ausência ativa da vontade nos faz compreender um pouco do conceito de vontade. Na "Ética a Nicômaco" onde é relatado de forma muito clara o pensamento de Sócrates acerca dessa questão, relato esse confirmado pelo "Protágoras" de Platão e pelo "Memoráveis" de Xenofonte (Cf. PLATÃO, Protágoras 352a-c; XENOFONTE, Memoráveis, apud REALE, 1993, vol. I, p.270). Dessa forma, A partir de uma leitura do relato de Aristóteles, evidencia-se que com a tese ética da virtude-ciência, onde uma vez que o indivíduo conhece, não é mais incontinente frente ao mal e as paixões, e se torna governado plenamente pela razão, não existe espaço para a vontade:

Assim pensava Sócrates, que existindo o conhecimento num homem, alguma coisa pudesse avassalá-lo e arrastá-lo após si como um escravo. Com efeito, Sócrates era inteiramente contrário á opinião em apreço, e segundo ele não existia isso que se chama incontinência. Ninguém depois de julgar - afirmava, age contrariando o que julgou melhor; os homens só assim procedem por efeito da ignorância (ARISTÓTELES, Ética a Nicômaco, 1145b, 25).

Segundo o que nos relatam os testemunhos doxográficos, Sócrates defendia um domínio absoluto da razão sobre a conduta moral humana, de forma que uma vez a alma, que na compreensão do filósofo é o próprio homem, possui o conhecimento verdadeiro (episteme) do bem, não pode escolher praticar o mal, e o mesmo acontece em sentido oposto, quem não conhece verdadeiramente o bem não pode escolher praticar o bem. Logo, o conhecimento do bem é condição necessária e suficiente para a prática do bem, de forma que o mal é praticado exclusivamente por ignorância, e não por ato da vontade. A razão tem seu papel acentuado, sendo determinante para ação moral, em detrimento da vontade que ao menos pelo que sabemos do pensamento do filósofo ateniense, nada determina. Quando a alma conhece, a razão impera no homem de forma que as paixões são absolutamente anuladas como fator determinante da ação. Aqui não cabe o querer, mas a determinação do conhecimento ou da ignorância.

O primeiro filósofo que trabalhou com o conceito em questão dedicando-lhe bem mais atenção foi Agostinho, pois mesmo sem escrever uma obra especificamente sobre ele, o trabalhou ao seu estilo, pulverizando o conceito em diversas obras. $O$ termo vontade, no latim voluntas foi amplamente usado por Agostinho com sentidos diversos a depender do contexto de uso. Todavia, o significado que frequentemente está associado ao filósofo cristão pela constância que fez uso do mesmo é que a voluntas é a faculdade da alma que dá a direção ao sujeito. Dessa forma, a vontade sem dúvida é o querer da alma, mas o querer que determina o uso das demais faculdades da alma. Como nos esclarece esse fragmento da obra do Agostinho maduro no "Sobre a Trindade" em que o filósofo cristão fala da trindade interior presente na alma que forma o pensamento, notadamente a vontade, a memória e a visão interior: 
[...] e a própria vontade, do mesmo modo que, no exterior, dirigida para o objeto corpóreo o senti a ser formado e, uma vez formado, a ele o juntava, assim também vira para a memória o olhar do espírito que recorda, para que a visão seja formada a partir daquilo que a memória guardou, e, no pensamento, gera-se uma visão igual (AGOSTINHO, De Trin., XI, 3, 6).

Assim, a vontade determina a direção da alma inclusive na própria formação do pensamento, pois como nos revelou a perícope supra, a memória dirige a atenção da alma para os objetos corpóreos, de forma que esses objetos são arquivados na memória formando uma visão interior, e quando convier à vontade, a alma dirige a sua atenção para esse objeto presente na memória em forma de visão interior formando o pensamento. Ou seja, a vontade está presente na formação do pensamento dirigindo a atenção da alma desde o começo até a execução do pensamento formado, de forma que é difícil exagerar sobre a importância da vontade para Agostinho'.

Destarte, no transcorrer histórico da filosofia foi se estabelecendo a ideia de que a vontade foi uma faculdade da inteligência divina ou da alma humana, logo, a vontade é um querer, mas um querer associado à capacidade da inteligência divina ou humana de escolher entre várias possibilidades. A vontade além de determinar o comportamento humano, não seria um exagero dizer que ela possui uma anterioridade ontológica com relação à razão, visto que, em última instância é a vontade que determina o uso que faremos de nossa razão. De forma que é a vontade unida com a razão, ou vontade consciente que determina nosso comportamento prático, e por que não dizer nossas pretensões de investigações teóricas.

$\mathrm{Na}$ ética moderna a vontade tem papel semelhante, pois em Kant emblematicamente ela determina o comportamento moral do indivíduo, todavia, em sua "Crítica da Razão Prática" o comportamento moral orientado adequadamente é aquele que os princípios morais puramente racionais determinam a vontade, e quando isso não acontece temos princípios morais misturados com experiências subjetivas, no primeiro caso a vontade é orientada pelo imperativo categórico universalizável, e no segundo as máximas subjetivas não universalizáveis. Assim, a despeito de ser dada certa importância à vontade, pois ela com o seu querer determina o comportamento moral, contudo, ela deve ser determinada pela razão pura prática, existindo assim uma clara superioridade da razão em relação à vontade no que tange ao comportamento prático do sujeito.

Em Friedrich Nietzsche, embora tenhamos algumas características da vontade que até aqui esboçamos, em certo aspecto existe uma ruptura nesse conceito dando ao mesmo uma superabundância até então inédita. Da mesma forma que no pensamento clássico (filosofia antiga, medieval e moderna), ela é um querer que determina o comportamento, todavia, para o pensador contemporâneo é um querer que determina o sentido da própria existência independente da razão, o que rompe com a tradição, visto que nessa última sempre houve um movimento do controle dessa poderosa força pelo intelecto. Para nosso pensador, a vontade determina plenamente o sentido da vida humana e de toda a realidade, assim, a vontade é potência que tudo determina, a existência humana como outrora, mas também de toda a

\footnotetext{
2 Agostinho frequentemente associa a vontade ao livre-arbítrio, visto que essa vontade que a princípio era livre, com o mau uso da mesma que gerou o pecado original foi danificada, gerando uma vontade que embora permaneça determinando o comportamento, se tornou incapaz de conduzir o homem para a escolha da felicidade suprema soteriológica (Cf. AGOSTINHO, De nat. et grat., III, 3). Assim, o livre-arbítrio é essa limitação na liberdade da vontade, que sem o auxílio da graça não pode escolher a salvação.
} 
realidade. A vontade de potência é o princípio vital de toda a realidade, ou dizendo de outra forma, a vida em sua plena natureza é vontade de potência.

Destarte, em Nietzsche, a vontade é o que fundamenta toda a realidade, a realidade é vontade de poder. Vontade de poder não é uma faculdade ou atributo, porém a essência da própria realidade, da própria vida, essência não no sentido platônico de protótipo inteligível e universal da realidade sensível, mas no sentido de natureza, de o que constitui uma determinada realidade. A vontade de poder é a essência da vida no sentido de que é o fundamento mais elementar sem o qual a vida não seria o que é. A vida segundo Nietzsche é um constante vir-aser, é uma possibilidade constantemente inacabada que em seu movimento sempre recria a si mesma, como acentua o pensador no "Assim Falou Zaratustra": "Este segredo a própria vida me confiou: "vê', disse, "eu sou aquilo que deve sempre superar a si mesmo" (NIETZSCHE, 1995, II, 12, p. 127). Esse superar a si mesmo é próprio do que a vida é, e o que possibilita esse movimento constante e sem meta da vida é a vontade de poder. A vontade de poder é a pulsão presente na vida, que a faz puro movimento, puro recriar-se, é o que faz com que a vida seja um abismo, abismo no sentido de que ela nunca está pronta. Visto que a vida é essencialmente este vir-a-ser que permanece em constante vir-a-ser, e que é a vontade de poder que possibilita que a vida assim seja, podemos dizer que de certa forma a vida em seu aspecto mais elementar é vontade de poder. Como aclara Nosso Filósofo: "A vontade de potência não é um ser, não é um vir-a-ser, mas um 'Pathos', ela é o fato elementar do qual resulta precisamente um vir-a-ser, um atuar" (NIETZSCHE, Apud., MOURA, 2005. p. 197).

A verdadeira pulsão que move e mantém a vida não é, como muitos dizem, o instinto de autoconservação, mas a vontade de poder, na medida em que a autoconservação é apenas uma consequência da pulsão elementar da vontade de poder ${ }^{3}$. Logo, o que faz com que a vida orgânica dirija-se para a autosobrevivência é justamente a vontade de poder. Porém, embora percebamos na vida orgânica a pulsão de vida como vontade de poder, esta última abrange toda a realidade, não apenas a vida orgânica. Segundo Nietzsche toda a realidade em seu acontecer é movida pela vontade de poder. A vontade de poder é a fonte do vir-a-ser da realidade, e na medida em que toda a realidade está em constante transformação, a fonte de toda a realidade é a vontade de poder, e visto que o vir-a-ser é o princípio imutável de uma realidade que tem impresso em sua essência a mutabilidade do vir-a-ser, a vontade de poder sempre retorna. Pois, apesar de tudo mudar, de tudo criar e recriar a sua existência, o que sempternamente não mudará é justamente esse vir-a-ser que faz da vida esse inacabado, e por isto a vontade de poder como movimento constante da vida, como pulsão e pathos de toda formação e transformação da realidade é algo que sempre retorna, sendo denominado pelo Filósofo como vontade de poder como eterno retorno.

Além do eterno retorno, outra idéia que está associada à vontade de poder é o superar a si mesmo, o superar a si mesmo envolve uma elevação de um determinado estado atual, e visto que um determinado estado envolve uma determinada limitação que o define, o superar a si mesmo significa superar o atual limite, e é claro que um transpor limite envolve enfrentar resistências. Nesse sentido, podemos dizer que a vontade de poder é um constante movimento de autosuperação em que está contido o enfrentamento de tensão e resistência. Por isso, percebemos em toda a realidade que quando o novo ou o diferente tenta se impor, enfrenta tensão e resistência. É com tensão e resistência que algo nasce na natureza orgânica, é com tensão e resistência que um novo poder político assume o comando de um Estado, enfim, a tensão e a resistência fazem

${ }^{3}$ Como disserta Nietzsche: "Uma criatura viva quer antes de tudo dar vazão à sua força - a própria vida é vontade de poder - : a autoconservação é apenas uma das indiretas, mais frequentes consequências disso" (NIETZSCHE, 1997, § 13). Ver também: NIETZCHE, 1995, p. 128. 
parte da auto-superação, e esta última participa da vontade de poder. Logo, vontade de poder é também tensão e resistência que está presente em todo movimento da vida. Como acertadamente comenta o professor Carlos Alberto de Moura:

Em todo corpo vivo realiza-se este caráter fundamental: ele precisará crescer, alcançar a preponderância - e isso não por alguma moralidade ou imoralidade, mas porque ele vive e a vida é vontade de potência. [...] se a vontade de potência requer a resistência, existe aqui um jogo, nunca uma guerra total (MOURA, 2005, p. 198, 199).

Embora a vontade de poder seja uma pulsão que move toda a realidade, na vida humana ela revela-se de maneira emblemática, assim sendo, todas as atividades, culturas, conhecimentos, organizações político-sociais, valores, religiões, filosofia, enfim, tudo o que poderíamos chamar de especificamente humano, são episódios transitórios da vontade de poder como eterno retorno. Logo, todas as verdades caras à Metafísica, denominada por Nietzsche de vontade de verdade, foram impulsionadas pela vontade de poder em seu eterno vir-a-ser, e longe de ser a verdade, não passam de um dos múltiplos aspectos da revelação da vontade de poder na vida humana, como disserta Nietzsche:

\begin{abstract}
'Vontade de conhecer a verdade' chamais vós, os mais sábios dentre os sábios, aquilo que vos impele e inflama? Vontade de que todo o existente possa ser pensado: assim chamo eu à vossa vontade! [...] E tu também, que buscas o conhecimento, é apenas uma senda e uma pegada da minha vontade; em verdade, a minha vontade de poder caminha com os pés da tua vontade de conhecer a verdade (NIETZSCHE, 1995, II, 12, p. 126, 128).
\end{abstract}

Na perícope supra, a vida dialogando com Zaratustra afirma que toda a vontade de conhecer dos filósofos da tradição metafísica é na verdade uma expressão da vontade de poder, ou seja, a vontade de poder se revela de inúmeras formas na vida humana, e uma delas é a sede de conhecimento que impulsiona os filósofos em sua constante investigação e teorização acerca da verdade. Portanto, a verdade racional metafísica não tem nenhuma primazia sobre a não verdade ou sobre o irracional, pois, todos têm a mesma pulsão vital, e ela a vontade de poder é a pulsão elementar de toda a realidade, tanto das investigações metafísicas como das instâncias não racionais da vida humana, por isso pergunta Nietzsche, por que a verdade em vez da não verdade?":

Que parte de nós tende "para a verdade?" Detivemo-nos ante o problema da origem dessa vontade, para ficar em suspenso diante de outro problema ainda mais importante? Interrogamo-nos sobre o valor dessa vontade. Pode ser que desejamos a verdade, mas por que afastar o não verdadeiro ou a incerteza e até a ignorância? Foi a problema da validade do verdadeiro que se colocou frente a nós ou fomos nós que o procuramos? (NIETZSCHE, 2001, §1).

Semelhantemente, os valores, sejam eles morais ou amorais, decorrentes de uma moral cristã ou atéia, são produtos da vontade de poder, como esclarece o filósofo com a metáfora do barco, no "Assim Falou Zaratustra":

Os ignorantes, sem dúvida, o povo - são como um rio onde um barco continua boiando; e no barco estão sentadas, solenes e mascaradas, as apreciações de valor. Colocastes a

\footnotetext{
${ }^{4}$ Comentando essa passagem, José Ferrater Mora afirma que o fundamento mais elementar das verdades ditas racionais é de fato fruto de uma pulsão instintiva, o pensamento racional é guiado pelos instintos (Cf. MORA, 2001, tomo IV, p. 3050).
} 
vossa vontade e os vossos valores no rio do devir; uma velha vontade de poder revela-me aquilo em que o povo acredita como sendo o bem e o mal. [...] agora o rio leva o barco: deve levá-lo. Pouco importa que a onda ao romper-se, espumeje e furiosa, se oponha à quilha! (NIETZSCHE, 1995, II, 12, p. 126).

Na belíssima metáfora que o Filósofo nos apresenta, os valores que estão no barco são apreciações de valor moral ou não moral, logo, no barco estão todos os valores morais do Cristianismo, todos os valores construídos pelos metafísicos, enfim, tudo aquilo que a humanidade em sua cultura deposita valor. Todos os valores que citamos, embora algumas vezes opondo-se uns aos outros, participam do mesmo barco, ou seja, embora muitas vezes contrários uns aos outros, todos os valores são fundamentados pela vontade de poder. Assim sendo, o bem e o mal, a verdade e a não verdade, a moral cristã e a pagã, são manifestações da vontade de poder em seu constante vir-a-ser. $O$ rio, como o próprio autor revela, é o povo, o povo que com sua cultura sustenta o barco dos valores para que ele permaneça boiando, ou seja, a cultura humana dá a esses múltiplos valores determinada estabilidade, porém, esta estabilidade não tardará em tornar-se instabilidade pelas mãos da própria fonte que outrora estabilizava o barco. Pois, o rio da cultura humana em um momento sustenta o barco, e em outro resiste ao barco com impetuosas correntes que furiosamente opõe-se a quilha. Quer dizer, o mesmo povo que possibilitou a estabilização dos valores em um determinado momento, visto que o homem é um constante inacabado, em outro momento se oporá a estes valores, porque essa tensão e resistência são próprias da vida, e tantos os valores como sua oposição revelam a vontade de poder como superação de si mesmo que sempre retorna.

Em suma, a vontade de potência de Nietzsche não se reduz a uma esfera psicológica, política ou biológica ${ }^{5}$, mas é um pathos que move toda a realidade, inclusive as três esferas citadas. Outrossim, segundo nosso filósofo existe uma realidade que em seu acontecer revela melhor que qualquer outra coisa a vida como vontade de poder, essa realidade é a Arte. A Arte em seu acontecer exprime singularmente o que de fato a vida é.

\section{A arte como vontade de poder}

Como já comentamos, a vida segundo Nietzsche é um constante criar e recriar sem uma teleologia pré-definida. É justamente por este aspecto que a Arte expressa de forma mais transparente o que a vida é, pois, a Arte é justamente o processo de criação e recriação sem uma finalidade para além da própria criação. A Arte na perspectiva do artista está sempre inconclusa e por isso ele não cessa de criar, é como se o artista de alguma maneira captasse o que a vida é, e revelasse isso em sua arte e no processo de criação. A Arte além de ser, como tudo o mais, movida pela vontade de poder, na medida em que ela mesma é uma pulsão pelo constante criar, revela de forma muito peculiar o pathos que é a vida como vontade de poder que sempre supera a si mesma.

Portanto, o artista em seu criar assemelha-se ao filósofo, visto que o artista tem uma força em sua forma de ver o mundo que o afasta do mundo ordinário, do mundo enquanto coisificado pela civilização, e este estranhamento com o real coisificado possibilita-lhe em seu criar uma abertura para uma realidade mais elementar, mais próxima do que verdadeiramente a vida é. Em cada criar e recriar do artista está implícito uma oposição ao que está constituído

\footnotetext{
${ }^{5}$ Muitos comentadores categorizam a vontade de poder de Nietzsche em uma dessas três esferas, porém, nos parece que isso é fruto da pressa em rotular o referido conceito nietzschiano como mais uma fundamentação metafísica (Cf. MOURA, 2005, p. 208-210).
} 
para fazer nascer uma realidade nova, e cada nova realidade recriada pelo artista é uma perspectiva de vida, e nisso mais uma vez ele exprime a vida, visto que a vida em sua essência mais elementar é essa pulsão de abertura para inúmeras perspectivas e possibilidades de vida. Como esclarece esse fragmento de $A$ vontade de poder:

É-se artista de mão cheia contanto que se sinta aquilo que todo não-artista chama de 'forma' como conteúdo, como 'coisa mesma'. Com isso, sem dúvida, se pertence a um mundo às avessas: pois doravante o conteúdo torna-se algo meramente formal - mesmo nossa vida (NIETZSCHE, 2008, § 818).

Portanto, o verdadeiro artista ao perceber contra a corrente do mundo a forma como conteúdo e o conteúdo como forma, percebe o mundo invertido, e essa inversão no olhar o possibilita brincar com a vida, criando e transformando o atual em novo. Além disso, na medida em que os valores contrapostos pelo artista são segundo Nietzsche uma mentira necessária para suportar a existência, em sua inversão da realidade encontra a verdadeira realidade em suas inúmeras realidades criadas. A vida em sua forma mais autêntica é terrível e abissal, e para suportar o caráter doloroso do que a vida é, o homem cria verdades estáveis com as quais eles possam viver, como bem expressa Nietzsche: "[...] temos necessidade da mentira para sobrepujarmos essa realidade, essa 'verdade', quer dizer, para vivermos... o fato de que a mentira seja necessária para viver pertence a esse caráter terrível e problemático da existência" (NIETZSCHE, 2008, § 853, 1).

As mentiras aqui ditas por nosso filósofo são as verdades da metafísica, os valores cristãos, a moral, a religião, a ciência, etc. Estas mentiras são necessárias para possibilitar suportar a existência, logo, neste sentido entendemos que o artista é um tipo de sacerdote da vida, porque ao ter a capacidade de ver a realidade contra a corrente do mundo ordinário, percebe o caráter abissal da vida, suportando assim um fardo difícil demais de carregar. $O$ artista verdadeiro é um sacerdote da vida em sua verdadeira face, talvez por isso muitos gênios da Arte são tidos como excêntricos ou loucos, ou muitas vezes ao não suportarem o fardo da vida em sua essência, enlouquecem de fato.

$O$ artista em seu processo de criação sofre, morrendo muitas vezes enquanto sujeito para criar o novo, porém, na medida em que este sofrer é condição sine quanon para o criar, o sofrer e a dor são acolhidos com carinho. Para o artista o sofrer é querido, e visto que essencialmente a vida é dor e sofrimento, o artista acolhe com carinho o que a vida é: "A arte como a redenção do sofredor, - como caminho para estados nos quais o sofrer é querido, transfigurado, divinizado; nos quais o sofrer é uma forma do grande arrebatamento" (NIETZSCHE, 2008, § 853, 2).

No final do parágrafo 796 de $A$ vontade de poder, diz Nietzsche que o mundo é "como uma obra de arte que dá à luz a si mesma" (NIETZSCHE, 2008, § 796), pois, como já comentamos, na obra de arte está em seu processo de criação representados tudo aquilo que a vida como vontade de poder é, e mesmo na própria obra visto que ela é uma perspectiva de vida, a vida também está representada. Logo, imaginemos se uma obra de arte, com todas as pulsões criadoras que nela estão envolvidas, pudesse sem medição do artista criar-se sozinha, seria exatamente igual ao que a vida é. A vida é como uma obra de arte que cria a si mesma porque cria e recria a partir de seus próprios escombros, na vida assim como na arte estão expressos criação, mas também destruição. No constante vir-a-ser da vida, a destruição é tão natural quanto à criação, mas visto que a vida não conta com matéria externa para o criar, cria a partir de sua própria destruição, seus escombros são a matéria prima para a sua pulsão criadora. Semelhantemente, o artista destrói perspectivas de vida, e a partir destes escombros constrói outras. Na arte da mesma forma que na vida como vontade de poder, o destruir e o criar 
necessitam um do outro para formarem respectivamente arte e vida, a vida é como a arte porque a arte revela a natureza da vida.

A pulsão criadora do artista segundo o filósofo é como uma espécie de jogo, de brincadeira de criar e recriar, pois, assim como uma criança utiliza toda a sua energia brincando, a Arte é um desperdício de força utilizada no jogo de criação. $O$ artista, assim como uma criança, despeja toda a sua força no brincar que é a criação, e isso só é possível porque ambos estão sobrecarregados de força. Assim sendo, da mesma forma que uma criança no seu brincar é uma metáfora do artista, ele é uma metáfora da vida na medida em que a vida é em sua natureza um desperdício de uma força criadora, que só é desperdiçada porque a ela está sobrecarregada de força: "[...] 'o jogo", o inútil - como ideal do sobrecarregado de força, como 'infantil'. A “infantilidade' de Deus, $\pi \alpha 1 \zeta \pi \alpha 1 \zeta \omega v "$ (NIETZSCHE, 2008, § 797). Como versa esta perícope, a criação é um jogo inútil, inútil no sentido de não existir uma meta além do próprio ato de criar, a meta da criação é a própria criação, nada além ou aquém disto. Isto é, a criança, a Arte e a própria vida em seu criar, cria como uma brincadeira inútil, sem nenhuma finalidade fora da própria brincadeira, não existe uma meta máxima evolutiva no devir da vida, mas o movimento é a sua própria meta, o devir é um vir-a-ser inútil.

Por tudo isso que supra comentamos, Nietzsche no $\S 853,4$ de $A$ vontade de poder ao comentar acerca do livro $O$ nascimento da tragédia, diz que o autor deste livro ao escrevê-lo vivenciou o seguinte: "Que a arte tem mais valor do que a verdade" (NIETZSCHE, 2008, § 853, 4). A verdade aqui criticada por Nietzsche é a concepção de verdade inaugurada pelo Socratismo e Platonismo, que de certa forma é fundamentada em uma espécie de divinização do conceito racional, pois, o conceito no sentido metafísico do termo, através de abstração racional o particular é universalizado, e essa abstração universal é o conceito, ou melhor, a verdade conceitual metafísica. Porém, questiona Nietzsche, por que a verdade racional-conceitual tem a primazia? Até que ponto a verdade é de fato a abstração racional e universal do particular? Nosso filósofo em explícita inversão do Platonismo afirma que a verdade racional-conceitualmetafísica tem menos valor que a irracionalidade do pathos artístico.

Essa afirmação de Nietzsche é considerada uma inversão do Platonismo porque vai de encontro com o que diz Platão acerca da Arte e da verdade. Pois, Platão em sua República, após muito criticar o conteúdo das poesias de Homero e Hesíodo, passa a criticar a forma da referida poesia que é mimética, e para isso utiliza o exemplo dos pintores, e acaba revelando sua opinião sobre este tipo de arte. Segundo ele, o pintor não passa também de um imitador que ao reproduzir as realidades sensíveis, imitam cópias das essências. Quer dizer, na medida em que os entes da Natureza já são cópias das formas arquétipas eternas ${ }^{6}$, a pintura que é uma cópia destes entes, é cópia da cópia, estando assim a três pontos da verdade, como revela esse trecho da República:

- Acaso não existem três formas de cama? Uma que é a forma natural, e da qual
diremos, segundo entendo, que Deus a confeccionou, [...] - outra, que executou o
marceneiro. - Outra, feita pelo pintor. Ou não? - Sim. - Logo, pintor, marceneiro, Deus,
esses três seres presidem aos tipos de leito $[\ldots .$.$] e do pintor, diremos também que é artífice$
e autor de tal móvel? - De modo algum, [...] - o título que me parece que se ajusta
melhor é o de imitador daquilo que os outros são artífices. [...] - Chamas por

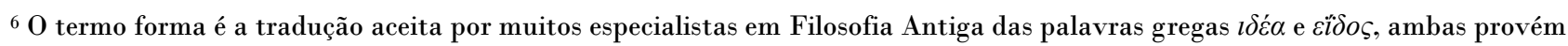
do vocábulo $i \delta \varepsilon i v$ que quer dizer ver, que em um período pré-platônico significava a forma visível das coisas. Os termos $\imath \delta \varepsilon ́ \alpha$ e $\varepsilon \ddot{l} \delta$ ऽ passaram a significar a forma interior dos seres, a Natureza ou essência das coisas, captada apenas pelo pensamento. Logo,

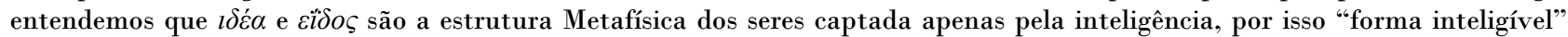
traduz esses termos usados por Platão (Cf. REALE, 1994, vol. II, p. 61-62).

BRANDÃO, Ricardo Evangelista. A arte como expressão da vida como vontade de poder em Friedrich Nietzsche. Griot : Revista de Filosofia, Amargosa - BA, v.20, n.2, p.190-201, junho, 2020. 
conseguinte, ao autor daquilo que está três pontos afastado da realidade, um imitador. (PLATÃO, 2007, Livro X, 579b-579e). ${ }^{7}$

Portanto, compreendemos que segundo a última perícope citada, a verdade é o aspecto da realidade chamada de realidade das formas inteligíveis, e só através da conceituação racional o homem pode ter acesso mais perfeito a essas realidades que inteligíveis são. A arte, na medida em que na compreensão de Platão é mimética, apenas tem acesso a essas realidades inteligíveis de forma muito obscura ${ }^{8}$. Diferentemente em Nietzsche, a arte, visto que percebe a realidade de forma invertida tomando como referência a realidade ordinária, tem a possibilidade na criação de outros aspectos da realidade, de ter acesso à essência da realidade, a aquilo que mais elementarmente a vida é. Parodiando invertidamente Platão, diríamos dizer que segundo Nietzsche a verdade conceitual é que está a três pontos da realidade, já que de certa maneira cada dita verdade, seja a conceitual-racional, a moral ou qualquer outra, é uma forma de negação da vida, e, assim sendo, "a arte como única força contrária superior, em oposição a toda vontade de negação da vida [...]" (NIETZSCHE, 2008, § 853, 2).

\section{Apólo e Dionísio como representação das forças artísticas que emergem da natureza9}

Na obra $A$ origem da tragédia, Nietzsche afirma que "consideramos até o momento o apolínico e seu contraste, o dionisíaco, como forças de arte que emergem da própria natureza [...] (NIETZSCHE, 2006, p. 41). Quer dizer, nosso pensador desde sua primeira obra publicada, ao teorizar acerca dos elementos fundantes da Tragédia Clássica Grega, admite que a tragédia de certa forma imita a natureza por ter presente os elementos apolínico e dionisíaco. Ou seja, na própria natureza existem elementos artísticos contrastantes que movem a vida, responsáveis pelo constante devir do criar e destruir, do nascer e do morrer, que posteriormente entendemos que será nomenclaturado por Nietzsche de vontade de poder. Para compreendermos a perícope supra, se faz necessário entender o que ele quer dizer com os termos natureza, apolínico e dionisíaco.

Natureza aqui usada por Nietzsche é a tradução do termo grego $\varphi v ́ \sigma l \varsigma$, que por sua vez provém do verbo $\varphi v ́ \omega$ que significa produzir, fazer crescer, gerar, formar-se, etc. Portanto, mais originariamente $\varphi v ́ \sigma ı \varsigma$ possui dois significados distintos, porém, complementares. Por um lado significa algo que "tem em si mesmo a força do movimento pelo qual chega a ser o que é no curso de um crescimento" (MORA, 2001. tomo III, p. 2271)10. Por outro lado, significa "o processo mesmo do 'emergir', do 'nascer', sempre que tal processo surja do ser mesmo que

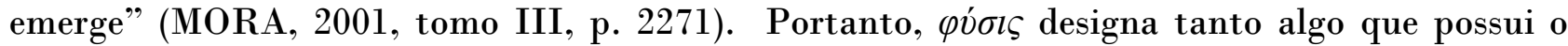

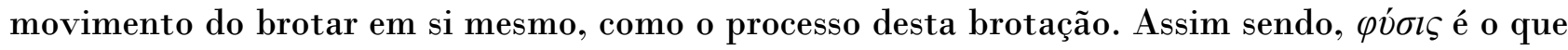
mais elementarmente a vida é, movimento, nascer, brotar, vir-a-ser, e segundo o pensador alemão o que garante esta brotação constante da $\varphi v ́ \sigma \iota \varsigma$ são as forças que emergem dela chamadas de apolínio e dionisíaco.

\footnotetext{
7 Não podemos esquecer o fato de que nessa época o objetivo da pintura artística era reproduzir o belo da Natureza com o máximo de exatidão possível.

${ }^{8}$ Não é apenas a pintura que possui essa estatura mimética para Platão, mas qualquer forma de Arte, qualquer forma de Arte é imitativa e conseqüentemente obscurece a verdade: "[...] A pintura é, de um modo geral, a arte de imitar, executa as suas obras longe da verdade, e, além disso, convive com a parte de nós mesmos avessa ao bom senso, sem ter em vista, nesta companhia e amizade, nada que seja são e verdadeiro" (PLATÃO, 2007, livro X, 603b).

9 Trabalhar o Apolínio e o Dinonisíaco em Nietzsche daria um artigo à parte, porém, nosso objetivo no escopo deste trabalho é apenas acentuar a idéia de que na vida em sua essência, as pulsões dionisíaca e apolínia estão presentes como forças artística da $\varphi v ́ \sigma \iota \varsigma, \log 0$, não contemplaremos temas como a embriaguez e formas de Arte opolínia e dionisíaca.

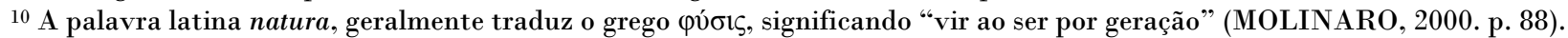

BRANDÃO, Ricardo Evangelista. A arte como expressão da vida como vontade de poder em Friedrich Nietzsche. Griot : Revista de Filosofia, Amargosa - BA, v.20, n.2, p.190-201, junho, 2020. 
Falando agora acerca do apolínio e dionisíaco como forças de brotação ( $\varphi v ́ \sigma l \varsigma)$ que a vida é, Nosso Filósofo vai buscar inspiração na mitologia grega, pois, percebe na $\varphi v ́ \sigma ı \varsigma$ elementos que identificam-se com esses dois deuses do panteão grego. Apolo $(A \pi \delta ́ \lambda \lambda \omega v)$, segundo os variados relatos da mitologia grega é um deus filho do deus supremo do Olimpo Zeus com ninfa Leto ${ }^{11}$ sendo sempre identificado como deus da luz, do sol, da harmonia, ordem e moderação. Por ser ligado à ordem é também o deus de todas as formas, e na medida em que todas as formas expressam de certa maneira um limite, igualmente é o deus dos limites ( $\pi \varepsilon \rho \alpha \varsigma)$. Já o Dionísio ( $\Delta \iota \omega ́ v v \sigma o \varsigma)$, é fruto do amor adulterino entre Zeus e a humana Semele, sendo sempre identificado com a escuridão, o êxtase, a orgia, o vinho, as festas sem limites, o sem limite ( $\alpha \pi \varepsilon i \rho \omega v)$ (Cf. MORA, 2001, tomo I, p. 164).

Assim sendo, Nietzsche afirma no fragmento supracitado que na brotação que a vida é, emergem a forma e a luz, e o informe e as trevas, o limite e a ordem, e o limitado e o desordenado, emergem Apolo e Dionísio. Essas duas forças opostas são artísticas na medida em que nesse constante opor-se, cria-se, como também destrói-se, e o que é Arte que não o jogo de criar e destruir? Portanto, a natureza em sua brotação está implícito consequentemente o morrer, pois, tanto o nascer como o morrer expressam o que a vida de fato é. A vida em seu estado mais elementar é pulsão de forças artísticas, e visto que o verdadeiro artista também em seu obrar cria e destrói, é uma forma de imitador por estar copiando em seu processo criativo o que a vida em sua mais crua realidade é. Como assevera o Filósofo: "[...] com respeito a estes estados artísticos imediatos da Natureza, é qualquer artista um imitador [...]" (NIETZSCHE, 2006, p. 41).

Levando em consideração que toda a realidade em seu estado mais elementar é vontade de poder, e que os elementos contrastantes apolínio e dionisíaco emergem da $\varphi v ́ \sigma \iota \varsigma$, podemos dizer que de certa forma o limite e o ilimitado, a forma e o abissal são características constituintes da vida como vontade de poder. Consequentemente esses elementos contrastantes que citamos fazem parte do eterno vir-a-ser que a vida é, visto que seja qual for a esfera da realidade observada, encontraremos elementos apolínicos e dionisíacos.

Segundo Nietzsche o grande problema da maneira como a civilização ocidental se desenvolveu, está no fato de que o homem entende que toda a realidade é apenas apolínia, perdendo assim a capacidade de perceber que a vida também é dionisíaca. Que a vida é forma e luz, mas também é trevas e abismo. Ambos são instâncias de manifestação do real, apesar de serem impulsos contrários, são contrários para criar e recriar dos próprios escombros o que a vida é. Embora com o Socratismo a ótica passe a ser apenas apolínia, Dionísio estará sempre presente, pois, Apolo é a forma com a qual Dionísio manifesta-se, e apesar de que em nossa configuração mental socrática perspectivamos apenas a luz, o visível e as formas. As trevas, o invisível e o amorfo, estarão sempre presentes fundamentando ocultamente o real. Não há limite sem um ilimitado para ser limitado, não há luz sem trevas para iluminar, não há formas sem o amorfo, não existe Apolo sem Dionísio, ou melhor, Apolo sempre será a maneira como Dionísio manifesta-se independente de nossa condição de percebê-lo.

Segundo Nietzsche, embora todo real compreendido como vontade de poder seja Apolínio de Dionisíaco, é na Arte que esses elementos se expressam de forma mais clara, mas em particular é na Tragédia Clássica que essas duas pulsões se expressam transparentemente: “A arte trágica, rica em ambas as experiências, é classificada como a confraternização do Apolo e Dionísio" (THEODOR, In: NIETZSCHE, 2006. p. 8.). Apolo estaria presente na palavra e

\footnotetext{
${ }^{11}$ Segundo a mitologia grega, a esposa de Zeus é Hera, logo todos os filhos que teve fora dessa união foram filhos adulterinos (Cf. MORA, 2001, tomo I, p. $163-164$ ).
} 
Dionísio no coro. Logo, a palavra e o coro da tragédia expressam de maneira peculiar as duas pulsões da vida em sua essência.

Em suma, toda a realidade, desde seus aspectos mais simples aos mais complexos como as conceituações da metafísica e estruturas organizacionais políticas e morais de Estados e das várias religiões existentes, e até mesmo a arte, são na prática Dionísio se manifestando por meio de Apolo, ou seja, é a vida em sua abissal explosão de forças se manifestando por meio de alguma forma. 


\section{Referências}

AgOSTINHO, Santo. O espírito e a letra. Trad. de Agustinho Belmonte. São Paula: Paulus, 1998.

AgostinhO, Santo. Trindade. Trad. de Arnaldo do Espírito Santo; Lucas Dias; João Beato.

São Paulo: Paulinas, 2007.

ARISTÓTELES. Ética a Nicômaco. Trad. de Leonel Vallandro. São Paulo: Abril Cultural, 1973. MOLINARo, Aniceto. Léxico de metafísica. Trad. de Benôni Lemos. São Paulo: Paulus, 2000.

MORA, José Ferrater. Dicionário de filosofia. Trad. de Maria Stela Gonçalves. São Paulo: Loyola, 2001.

MOURA, Carlos Alberto de. Nietzsche: Civilização e cultura. São Paulo: Martins Fontes, 2005.

NIETZSCHE, Friedrich Wilhelm. Assim falou Zaratustra: um livro para todos e para ninguém. Trad. de Mário da Silva. Rio de Janeiro: Bertrand Brasil, 1995.

NIETZSCHE, Friedrich Wilhelm. Além do bem e do mal: prelúdio de uma filosofia do futuro. Trad. de Márcio Pegliesi. Curitiba: Hemus Livraria, 2001.

NIETZSCHE, Friedrich Wilhelm. Além do bem e do mal: prelúdio a uma filosofia do futuro. Trad. de Paulo César de Souza. São Paulo: Companhia das Letras, 1997.

NIETZSCHE, Friedrich Wilhelm. A vontade de poder. Trad. de Marcos Sinésio Pereira Fernandes; Francisco José Dias de Moraes. Rio de Janeiro: Contraponto, 2008.

NIETZSCHE, Friedrich Wilhelm. A origem da tragédia: proveniente do espírito da música. Trad. de Erwin Theodor. São Paulo: Ebooksbrasil, 2006.

PLATÃO. A república. Trad. de Maria Helena da Rocha Pereira. Lisboa: Fundação Calouste Gulbenkian, 2007.

PLATÃO. Protágoras. Trad. de Edson Bini. São Paulo: Edipro, 2007.

REALE, Giovanni. História da filosofia antiga. Trad. de Henrique Cláudio de Lima Vaz. São Paulo: Loyola, 1993.

REALE, Giovanni. História da filosofia antiga. Trad. de Henrique Cláudio de Lima Vaz. São Paulo: Loyola, 1994.

THEODOR, Erwin. Prefácio. In: NIETZSCHE, Friedrich. A origem da tragédia: proveniente do espírito da música. São Paulo: Ebooksbrasil, 2006.

Autor(a) para correspondência: Ricardo Evangelista Brandão, Estrada do Alto do Moura, km 3.8, Distrito Industrial III, 55040-120, Caruaru-PE, Brasil. E-mail: ricardobrand75@gmail.com 